\title{
Pengaruh Citra Merek Terhadap Keputusan Pembelian Smartphone Iphone pada Mahasiswa Fakultas Ekonomi Universitas Batanghari
}

\author{
Riko Mappedeceng \\ Fakultas Ekonomi Universitas Batanghari \\ Corresponding author: rikomappedeceng@gmail.com
}

\begin{abstract}
The reason researchers chose the brand image against the decision to buy an iPhone smartphone in students of the Faculty of Economics, Batanghari University. To find out the brand image influences the decision to buy iPhone smartphones in students of the Faculty of Economics, Batanghari University, 2. To find out the influence of brand image on the decision to buy iPhone smartphones on students of the Faculty of Economics, Batanghari University. This study is descriptive to test hypotheses, this study sample is a student of the Faculty of Economics, Batanghari University which numbered 95 respondents by spreading questionnaires collection techniques using questions. Apple inc. It is a multinational corporation based in Silicon Valley, Cupertino, California and engaged in the design, development, and sale of goods that include consumer electronics, computer software, and personal computers. Apple Inc. It was founded on April 1, 1976 and was incorporated into Apple Computer, Inc. On January 3, 1977. On January 9, 2007, the word "computer" was removed to reflect Apple's focus on consumer electronics after the launch of the iPhone. SPSS Results equation $Y=1.190+0,607$ X from this equation, it can be said that brand image variabel can be used as a tool to predict purchasing decisions smartphone iPhone. The influence brand image on purchasing decision smartphone iPhone is 0,607. The relationship between variable brand image on the purchasing decision of smartphone iPhone the strong relationship has an effect on the strength of the influence between the two variables which can be seen from the correlation coefficients of 0,969 This model is able to explain 0,940 based on purchasing decision variables while 6\% explained of this study is that the overall influence brand image on purchasing decisions is very good based on the hypothesis it is a positive known that there is relationship between brand image and purchasing decisions.
\end{abstract}

Keywords: Brand image and purchasing decisions

\section{Pendahuluan}

Kemajuan teknologi saat ini sudah menjadi bagian dari kehidupan sehari-hari manusia dan sudah menjadi sesuatu yang penting dalam hubungan sosial masyarakat. Perkembangan indusrti smartphone di Indonesia saat ini sedang mengalami peningkatan yang besar. Semua golongan masyarakat dari bawah sampai atas dapat menggunakan smartphone dalam berbagai keperluan, baik untuk urusan bisnis, keluarga, atau keperluan lainnya. Terdapat beberapa merek smartphone yang bersaing di Indonesia antara lain Samsung, Apple, Xiaomi dan lain-lain. Pasar smartphone seperti ini menyebabkan persaingan yang ketat diantara para kompetitor usaha di bidang telekomunikasi. Produk smartphone yang menguasai pangsa pasar di Indonesia diperkenalkan oleh beberapa perusahaan besar seperti Apple dan Samsung. Tingginya tingkat persaingan smartphone menuntut perusahaan seperti Apple dan Samsung berusaha menciptakan image yang kuat terhadap mereknya untuk memenangkan hati pelanggan. Belum lagi masuknya pemain baru seperti Huawei, Oppo, Xiaomi, dan brand keluaran Cina yang menawarkan harga lebih murah dengan kualitas hampir sama. Hal ini dapat meningkatkan kompetisi dan keputusan konsumen. Sebuah perusahaan harus memiliki keunggulan kompetitif yang sangat ditentukan oleh kemampuan perusahaan tersebut dalam memberikan nilai yang lebih tinggi dibandingkan kompetitornya. Oleh sabab itu, perusahaan wajib memahami apa yang dibutuhkan dan diinginkan oleh konsumen sehingga konsumen memutuskan untuk membeli produk atau jasa yang ditawarkan. Apple menjadi salah satu merek yang banyak diminati konsumen, itu karena Apple dengan sangat bagus membranding produk mereka termasuk produk iPhone. Apple berhasil menciptakan persepsi dalam benak konsumen terhadap smartphone iphone dengan sangat baik. Bahkan tidak sedikit juga konsumen yang tertarik untuk membeli smartphone iphone walaupun itu smartphone dengan status bekas pakai dan rekondisi. Walaupun iphone banyak diminati konsumen, tapi di Indonesia sendiri iphone belum bisa menguasai pasar Indonesia dikarenakan harganya yang cukup terbilang mahal dan hal itulah yang membuat iphone menjadi smartphone yang ekslusif terlepas dari kualitas produknya memang sangat baik.

Di kota Jambi banyak masyarakat yang lebih memilih smartphone yang dapat menunjang penampilan mereka, bahkan sudah menjadi fenomena kalau memakai smartphone iphone akan lebih percaya diri dan berkelas sehingga banyak orang juga membeli smartphone iphone dalam keadaan bekas pakai yang masih layak dan juga rekondisi. Apple berhasil menempatkan posisinya di konsumen yang lebih terfokus dibanding para pesaingnya, Apple dengan nyaman menempatkan dirinya di konsumen menengah atas hingga konsumen kelas atas. Tak dipungkiri bahwa Android mengungguli iphone dari segi penjualan, namun dari segi kualitas persaingan keduanya tak perlu lagi dibandingkan meski banyak yang menyebut iphone jauh lebih baik. Alasan mendasar mengapa penjualannya sedikit dibanding android adalah karena harganya yang mahal. Namun terlepas dari citra merek yang dimiliki smartphone 
iphone sudah bagus dan hal itu yang menjadi salah satu faktor konsumen untuk membeli produk itu, smartphoneiphone juga memiliki kekurangan yang membuat penggunaannya merasa terganggu dalam menggunakan gadgetnya dalam kegiatan sehari-hari. Biasanya masalah paling mengganggu yang dialami pengguna iphone yaitu tidak mendukung penyimpanan eksternal, iphone panas saat di-charge, iphone mudah panas dan mendadak mati, baterai boros dan cepat habis, kabel charge mudah rusak. Walaupun mereka mengeluh dengan kekurangan yang dimiliki iphone, tetapi mereka tetap membeli produk tersebut karena kebanyakan dari mereka memilih iphone karena berpikir citra merek yang dimiliki iphone sangat bagus. Dengan kata lain, strategi apple inc. dengan membangun brand image yang sedemikian rupa telah berhasil mempengaruhi konsumen untuk melakukan keputusan pembelian. Hal tersebut juga dibuktikan secara empiris bagaimana citra merek yang dimiliki oleh iphone mempengaruhi keputusan pembelian yang dilakukan oleh konsumen. Berdasarkan fenomena di atas maka peneliti tertarik untuk menganalisa atar Pengaruh Citra Merek Terhadap Keputusan Pembelian Smartphone Iphone Pada Mahasiswa Fakultas Ekonomi Universitas Batanghari. Tujuan penelitian ini untuk mengetahui pengaruh citra merek dan keputusan pembelian smartphone iPhone pada mahasiswa Fakultas Ekonomi Universitas Batanghari.

\section{Landasan Teori \\ Citra Merek}

Merek merupakan unsur penting yang dapat membantu proses pemasaran barang didalam perusahaan sehingga perusahaan semakin menyadari bahwa merek merupakan asset perusahaan yang paling bernilai dan menjadi instrument yang penting. Lebih dari itu merek adalah janji perusahaan secara konsisten untuk memberikan featurs, benefits, dan service kepada para pelanggannya. Citra merek terjadi karena keyakinan konsumen akan memperoleh kualitas barang dan jasa yang sama jika mereka membeli ulang pada merek yang sama setelah mereka membeli merek sebelumnya. Citra merek merupakan suatu persepsi dari konsumen tentang suatu merek dimana berdasarkan memori konsumen tentang suatu produk, sebagai akibat dari apa yang dirasakan oleh seseorang terhadap merek tersebut. Menurut Pradipta (2012) citra merek merupakan pepresentasi dari keseluruhan persepsi terhadap merek dan dibentuk dari informasi dan pengalaman masa lalu terhadap merek itu. Citra merek memiliki beberapa indikator-indikator yang mencirikan citra merek tersebut. Menurut Yulia (2015) indikator-indikator citra merek, diantaranya adalah Recognition (pengenalan), Reputation (reputasi), Affinity (daya tarik), Loyality (kesetiaan). Apabila sebuah merek telah dikenal oleh masyarakat, serta memiliki track record yang baik dimata konsumen maka akan menimbulkan daya tarik bagi konsumen dan konsumen tersebut akan menjadi konsumen yang loyal terhadap merek tersebut.

\section{Keputusan Pembelian}

Menurut Kotler \& Amstrong (2016) keputusan pembelian konsumen tidak terlepas dari bagaimana konsumen melalui beberapa tahap yaitu mengetahui masalah yang dihadapi sampai dengan terjadinya transaksi pembelian konsumen. Menurut Kotler dan Keller (2012) proses keputusan pembelian dipengaruhi oleh psikologis dasar dimana hal tersebut berperan penting dalam memahami bagaimana konsumen membuat keputusan pembelian mereka. Tujuan dalam membeli sebuah produk yaitu: 1) Konsumen akan melakukan pembelian ketika konsumen dapat mengenali kebutuhan, kebutuhan tersebut dapat dicetuskan oleh ransangan internal (kebutuhan umum seseorang) atau eksternal (ransangan pihak luar, misalnya iklan). 2) Pemrosesan informasi untuk pemilihan merek konsumen yang teransang kebutuhannya akan mulai terdorong untuk mencari informasi tentang merek melalui teman, keluarga, atau lingkungan sekitarnya. 3) Kemantapan pada sebuah produk. Keputusan yang dilakukan konsumen setelah mempertimbangkan berbagai informasi yang mendukung pengambilan keputusan. 4) Memberikan rekomendasi kepada orang lain. Merupakan penyampaian informasi yang positif kepada orang lain agar tertarik untuk melakukan pembelian. 5) Melakukan pembelian ulang. Merupakan pembelian yang berkesinambungan, serta konsumen merasakan kenyamanan atas produk atau jasa yang diterima.

\section{Metode}

Metode penelitian yang digunakan dalam penelitian ini adalah metode deskriptif kuantitatif, yaitu berusaha mendeskripsikan segala sesuatu yang ada di lapangan yang berhubungan dengan citra merek yang mempengaruhi keputusan pembelian. Untuk menyusun suatu karya ilmiah diperlukan data, baik berupa data primer maupun data sekunder, yaitu akan dijelaskan sebagai berikut: 1) Data Primer adalah data yang didapat dari sumber pertama baik dari individu atau perseorangan, seperti hasil wawancara atau hasil pengisian kuesioner. Umar (2010). 2) Data sekunder adalah data primer yang telah diolah lebih lanjut dan disajikan baik oleh pihak pengumpul data primer atau oleh pihak lain. Data sekunder disajikan antara lain dalam bentuk tabel-tabel atau diagram-diagram. Data sekunder ini digunakan oleh peneliti untuk diproses lebih lanjut Umar (2010). Sumber data dalam penelitian ini adalah mengenai smartphone iPhone yang dipakai di kalangan mahasiswa fakultas ekonomi Universitas Batanghari, yang diambil melalui wawancara dengan menyebar kuesioner, data, dan informasi yang diperoleh dianalisis secara deskriptif, untuk menganalisis respon mengenai keputusan pembelian yang menggunakan skala 5 pilihan. Guna memperoleh data yang 
lengkap untuk menunjang penelitian ini, maka diadakan pengumpulan data melalui: Penelitian Pustaka (library research). Penelitian Lapangan (field research). Populasi dari penelitian adalah mahasiswa fakultas ekonomi Universitas Batanghari yang berjumlah 1749 mahasiswa. Sampel yang dapat diambil dari teknik slovin adalah jumlah populasi dalam penelitian ini sebanyak 1749 orang, maka untuk mengetahui sampel penelitian dengan perhitungan jumlah sampel yang akan diambil adalah sebanyak 95 orang responden.

Analisis deskriptif adalah metode analisis dengan pendekatan kuantitatif yang bertujuan menggambarkan secara sistematis menggunakan skala likert. Skala likert, yaitu dengan memberikan nilai dari setiap pertanyaan yang diberikan dalam daftar pertanyaan.Nilai skor setiap variabel ditentukan pada rentang skala. Dengan rentang skala dapat diketahui skala penilaian setiap criteria atau variabel, yaitu sangat tidak setuju, tidak setuju, cukup setuju, setuju, dan sangat setuju. Kuesioner ini berbentuk pertanyaan tertutup dimana alternatif jawabannya telah tersedia dari $1-5$ (menggunakan skala likert format 5 jawaban) seperti berikut ini:

Tabel 1

Skala Likert

\begin{tabular}{lcc}
\hline \multicolumn{1}{c}{ Jawaban Responden } & Singkatan & Bobot \\
\hline Sangat tidak setuju & STS & 1 \\
Tidak setuju & TS & 2 \\
Cukup setuju & CS & 3 \\
Setuju & S & 4 \\
Sangat setuju & SS & 5 \\
\hline
\end{tabular}

Sumber: Umar (2010)

Untuk menganalisis permasalahan diatas digunakan skala penelitian dengan menghitung frekuensi skor setiap item pertanyaannya.Seperti yang dikemukakan Umar (2010). Bahwa perhitungan skor setiap komponen yang diteliti dengan mengalikan seluruh frekuensi data dengan nilai bobot.

Rumus yang digunakan adalah:

Skor terendah $=$ Bobot terendah $\mathrm{x}$ jumlah sampel $=1 \times 95=95$

Skor tertinggi $=$ Bobot tertinggi $\mathrm{x}$ jumlah sampel $=5 \times 95=475$

Untuk mencari rentang skala menurut Umar (2010) digunakan rumus sebagai berikut:

$\mathrm{n}: \frac{(m-1)}{m}$

Dimana: $\mathrm{n}=$ jumlah sampel $\mathrm{m}=$ jumlah alternatif jawaban

Rentang skala $=\frac{95(5-1)}{5}=76$

Tabel 2

Rentang Skala

\begin{tabular}{lcc}
\hline & Skor & Kategori \\
\hline $95-170$ & & Sangat tidak setuju \\
$171-246$ & Tidak setuju \\
$247-322$ & Cukup setuju \\
$323-398$ & Setuju \\
$399-475$ & & Sangat setuju \\
\hline
\end{tabular}

Sumber: Umar (2010)

Untuk menganalisis data yang diperoleh dari hasil penelitian dilapangan, digunakan analisis kuantitatif. Analisis kuantitatif digunakan untuk membuktikan hipotesis yang diajukan dengan menggunakan model analisis regresi linier sederhana, sedangkan analisis kualitatif digunakan untuk menelaah pembuktian analisis kuantitatif. Pembuktian ini dimaksud untuk menguji variasi dari model regresi yang digunakan dalam menerangkan variabel bebas $(\mathrm{X})$ terhadap variabel terikat $(\mathrm{Y})$ dengan cara menguji kemaknaan dari koefisien regresinya. Hasil perhitungan dengan menggunakan model regresi sederhana diperoleh dengan nilai koefisien regresi dari citra merek terhadap keputusan pembelian .

Tabel 3

Hasil Analisis Regresi Linier Sederhana

\begin{tabular}{|c|c|c|c|c|c|c|}
\hline & \multirow[b]{2}{*}{ Model } & \multicolumn{2}{|c|}{ Unstandardized Coefficients } & \multirow{2}{*}{$\frac{\text { Standardized Coefficients }}{\text { Beta }}$} & \multirow[b]{2}{*}{$\mathbf{t}$} & \multirow[b]{2}{*}{ Sig. } \\
\hline & & B & Std. Error & & & \\
\hline \multirow[t]{2}{*}{1} & (Constant) & 1.190 & .261 & & 4.557 & .000 \\
\hline & citra merek & .607 & .074 & .648 & 8.202 & .000 \\
\hline
\end{tabular}

Sumber: data olahan 
Berdasarkan tabel di atas diperoleh persamaan regresi linier sederhana dalam penelitian ini adalah: $\mathrm{Y}=1.190$ + 0,607.X. Model regresi tersebut dapat dijelaskan bahwa, nilai konstanta sebesar 1.190 artinya apabila vaiabel independen yaitu citra merek $(\mathrm{X})$ bernilai 0,670 , maka variabel dependen $(\mathrm{Y})$ keputusan pembelian akan bernilai tetap sebesar 1.190. Dari hasil persamaan regresi tersebut diketahui bahwa variabel citra merek berpengaruh positif terhadap keputusan pembelian jika variabel citra merek (X) mengikat sebesar satu satuan, maka variabel keputusan pembelian (Y) meningkat sebesar 0,607 satuan.

Tabel 4

Tabel Uji Koefisien Determinasi

\begin{tabular}{|c|r|r|r|r|}
\hline Model & R & R Square & Adjusted R Square & Std. Error of the Estimate \\
\hline 1 & $.648^{\mathrm{a}}$ & .420 & .413 & .44587 \\
\hline
\end{tabular}

Sumber: data olahan

Berdasarkan hasil pengujian koefisien determinasi pada tabel diatas, menunjukan bahwa nilai $\mathrm{R}$ square sebesar 0.420 yang artinya bahwa besarnya kontribusi variabel independen yaitu $\mathrm{X}$ citra merek mempengaruhi Variabel Y keputusan pembelian $42 \%$ sedangkan sisanya 58\% dipengaruhi oleh variable-variabel lain diluar penelitian ini.

Tabel 5

Hasil Pengujian Hipotesis Uji t

\begin{tabular}{|c|c|c|c|c|c|c|c|c|}
\hline \multirow{2}{*}{\multicolumn{2}{|c|}{ Model }} & \multicolumn{2}{|c|}{ Unstandardized Coefficients } & \multirow{2}{*}{$\frac{\text { Standardized Coefficients }}{\text { Beta }}$} & \multirow[b]{2}{*}{$t$} & \multirow[b]{2}{*}{ Sig. } & \multicolumn{2}{|c|}{ Collinearity Statistics } \\
\hline & & B & Std Error & & & & Tolerance & VIF \\
\hline \multirow[t]{2}{*}{1} & (Constant) & 1.190 & .261 & & 4.557 & .000 & & \\
\hline & citra m erek & .607 & .074 & .648 & 8.202 & .000 & 1.000 & 1.000 \\
\hline
\end{tabular}

Sumber: data olahan

Hasil pengujian diperoleh nilai probabilita untuk variabel citra merek sebesar 0. Dengan tingkat keyakinan $(\alpha=5 \%)$, dari perhitungan tersebut dapat dilihat bahwa nilai probabilitas lebih kecil dari alpha $(0<0,05 \%)$, artinya Ho ditolak dan Ha diterima artinya variabel citra merek berpengaruh signifikan terhadap keputusan pembelian smartphone iPhone pada mahasiswa Fakultas Ekonomi Universitas Batanghari.

Karakteristik mahasiswa fakultas ekonomi Universitas Batanghari yang dijadikan responden yaitu 95 responden, berdasarkan jenis kelamin smartphone iPhone yang paling banyak menggunakannya adalah perempuan yang berusia 21-23 tahun dengan uang saku perbulan $\mathrm{Rp} 1.000 .000$ - Rp 1.999 .000 dan telah lama menggunakan smartphone iPhone dalam kurun waktu 1 tahun -2 tahun. Peryataan tersebut terdapat kedalam beberapa faktor yang mempengaruhi perilaku konsumen yang meliputi faktor pribadi yang dimana faktor pribadi meliputi usia, keadaan ekonomi, kepribadian, dan konsep diri, serta gaya hidup. Pelaksanaan citra merek pada smartphone iPhone yang memiliki skor tertinggi adalah dari indikator loyality (kesetiaan) yang pernyataannya tidak memiliki keinginan berpindah dari smartphone merek iPhone ke smartphone merek lain dengan skor 408 berada pada interval sangat setuju, lalu selanjutnya terhadap indikator reputation (reputasi) yang pernyataannya smartphone merek iPhone memiliki reputasi yang baik dengan skor 404 berada pada interval sangat setuju, dan selanjutnya affinity (daya tarik) yang pernyataannya timbul kebanggaan saat menggunakan smartphone iPhone dengan skor 394 berada pada interval setuju, dan selanjutnya untuk skor terendah terhadap indikator recognition (pengenalan) yang pernyataannya logo smartphone mudah diingat dan mudah dikenali hanya dalam sekali melihat dengan skor 391 berada pada interval setuju. Dari keterangan di atas menunjukkan bahwa responden sangat setuju bahwa mereka tidak memiliki keinginan berpindah dari smartphone merek iPhone ke smartphone merek lain karena dari segi citra merek yang telah dibangun oleh perusahaan Apple Inc itu sangat baik.

Pelaksanaan keputusan pembelian terhadap indikator yang memiliki skor tertinggi adalah kemantapan pada sebuah produk yang pernyataannya keinginan untuk membeli smartphone sudah ditetapkan karena kualitas produk yang baik dengan skor 408 berada pada interval sangat setuju, lalu diikuti indikator pemrosesan dalam memilih informasi yang pernyataannya mencari informasi mengenai smartphone iPhone melalui teman, keluarga, atau kenalan dengan skor 407 berada pada interval sangat setuju, selanjutnya indikator melakukan pembelian ulang yang pernyataannya jika ingin membeli handphone lagi maka akan membeli smartphone iPhone dengan skor 402 berada pada interval sangat setuju, selanjutnya indikator tujuan dalam membeli sebuahproduk yang pernyataannya membeli smartphone iPhone karena memiliki kesan berkelas dan meningkatkan rasa percaya diri ketika menggunakannya dengan skor 399 berada pada interval sangat setuju, dan untuk skor terendah terhadap indikator memberikan rekomendasi kepada orang lain yang pernyataannya merasa terkesan dengan smartphone iPhone dan akan memberikan rekomendasi kepada orang lain untuk membeli smartphone iPhone dengan skor 392 berada pada interval setuju. Dari 
keterangan diatas menunjukkan bahwa responden sangat setuju bahwa mereka membeli smartphone iPhone dikarenakan kualitas produk yang dimiliki iPhone sangat baik sehingga responden memantapkan diri untuk membeli produk tersebut, lalu untuk skor terendah responden setuju bahwa mereka merasa terkesan dengan smartphone iPhone dan akan merekomendasikan kepada orang lain untuk membeli smartphone iPhone

Alasan pernyataan ini mendapatkan skor terendah dikarenakan yaitu kekurangan yang dimiliki iPhone seperti baterai yang boros, iPhone yang mudah panas dan mendadak mati, serta kabel charge yang mudah rusak. Berdasarkan persamaan hasil regresi diketahui atau diperoleh signifikansi F-sig sebesar 0,000 lebih kecil dari 0,05. Kemudian hasil uji t variabel citra merek berpengaruh signifikan terhadap keputusan pembelian karena nilai probabilita lebih kecil dari alpha $(0,000<0,05)$, Artinya Ho ditolak dan Ha diterima. Hal ini dapat diartikan bahwa variabel citra merek secara parsial berpengaruh signifikan terhadap variabel keputusan pembelian. Hasil ini sependapat dengan penelitian yang dilakukan Muh Ichwan Musa (2017) dalam penelitiannya yang berjudul pengaruh citra merek terhadap keputusan pembelian smartphone Samsung pada mahasiswa Universitas Negeri Malang bahwa citra merek berpengaruh signifikan terhadap keputusan pembelian.Berpengaruhnya citra merek terhadap keputusan pembelian dikarenakan kedua variabel tersebut saling terkait dalam kehidupan sehari-hari, perilaku konsumen dalam membuat keputusan disebabkan karena faktor citra merek yang baik. Semakin baik citra suatu produk dalam pandangan konsumen maka akan semakin banyak peminat dalam membeli produk tersebut.Hasil penelitian ini juga sesuai dengan teori Sangadji dan Sopiah (2013:337-338) citra merek adalah seperangkat ingatan yang ada di benak konsumen mengenai sebuah merek, baik itu positif maupun negative. Citra merek yang positif memberikan manfaat bagi produsen untuk lebih dikenal konsumen, dengan kata lain konsumen akan menentukan pilihannya untuk membeli produk yang mempunyai citra merek yang baik. Begitu pula sebaliknya, jika citra merek negatif konsumen cenderung mempertimbangkan lebih jauh lagi ketika akan membeli produk.

Citra merek sangat berpengaruh positif terhadap keputusan pembelian dimana konsumen akan memutuskan untuk membeli karena produk tersebut memiliki citra atau kesan yang sangat baik, jika dilihat dari hasil uji koefisien determinasi bahwa variabel citra merek memiliki pengaruh terhadap keputusan pembelian sebesar $42 \%$ sisanya $58 \%$ dipengaruhi faktor-faktor lain atau variabel-variabel diluar penelitian seperti kualitas produk, harga, atau pengaruh gaya hidup, dan sebagainya.

\section{Simpulan}

Pelaksanaan citra merek dan keputusan pembelian pada mahasaiswa Fakultas Ekonomi Universitas Batanghari baik. Untuk variabel citra merek mendapatkan rata-rata 399,3 dengan keterangan sangat setuju dan variabel keputusan pembelian mendapatkan rata-rata 401 dengan keterangan sangat setuju. Citra merek berpengaruh signifikan terhadap keputusan pembelian pada mahasiswa fakultas ekonomi Universitas Batanghari. Berdasarkan dari hasil uji koefisien determinasi terlihat bahwa citra merek memberikan pengaruh terhadap keputusan pembelian sebesar $42 \%$ yang sisanya 58\% dipengaruhi variabel lain seperti kualitas produk, harga, atau pengaruh gaya hidup. Lalu nilai persamaan regresi linear sederhana variabel citra merek terhadap keputusan pembeliandiketahui atau diperoleh signifikansi F-sig sebesar 0,000 lebih kecil dari 0,05. Artinya Ho ditolak dan Ha diterima. Kemudian hasil uji t variabel citra merek berpengaruh signifikan terhadap keputusan pembelian karena nilai probabilita lebih kecil dari alpha $(0,000<0,05)$, artinya Ho ditolak dan Ha diterima.

\section{Daftar Pustaka}

Kotler, Philip, Kevin Lane Keller. 2009. Manajemen Pemasaran. Edisi ketiga belas. Jakarta. Penerbit Erlangga Kotler, Philip, Gary Amstrong. 2016. Prinsip-prinsip Pemasaran. Edisi Ketiga Belas. Jilid 2. Jakarta: Erlangga Pradipta, Diah Ayu Anisa 2012. Pengaruh Citra Merek (Brand Image) terhadap Loyalitas Konsumen Umar, Husein. 2010. Riset Pemasaran dan Perilaku Konsumen.Jakarta: Gramedia Pustaka Utama Yulia. 2015. Dimensi Citra Merek terhadap Keputusan Pembelian Produk Oriflame (Studi Kasus pada Member PT. Orindo Alam Ayu Cabang Palembang) 